\title{
CHANGES IN THE FUNDUS CAUSED BY POLYCYTHAEMIA*
}

\author{
BY \\ F. NAGY \\ From the Second Eye Clinic of the Péter Pázmany University, \\ Budapest, Hungary.
}

THE aetiology of polycythaemia vera is unknown. This disease mainly consists in a remarkable increase in the red blood corpuscles and in the entire quantity of the blood. It is more frequent in men, mostly between the ages of 40 and 50 . Generally there is hyperaemia of the face, the conjunctiva, and the fundus. The presence of a spleen tumour is important. The changes in the fundus are more or less those called cyanosis retinae by Liebreich, and when we speak of fundus polycythaemicus this is in our mind, although Liebreich described these changes in connection with morbus coeruleus. The colour of the fundus is darker red, the veins are greatly enlarged and tortuous. Very many veins are visible because even the smallest veins are filled with blood.

Besides all these changes, papilloedema was described by Behr and Hegner, haemorrhages of the retina and of the vitreous by Litauer and Januszeveski (1934), and newly-formed vessels by Ohashi and Okada (1939). Uhthoff (1906) observed characteristic dilatations of the larger veins, and Behr dilatations of the capillaries, which according to them do not occur with other diseases.

The above-mentioned changes do not, however, explain the temporary deterioration of vision of which most patients suffering from polycythaemia complain. Generally it lasts for a few minutes, mostly on one side. Raynaud pointed out that spasm of the central retinal artery might account for cases of temporary sudden loss of sight. In two cases of polycythaemia Elschnig and Nonnenbruch (1932) found unilateral embolism of the central retinal artery and believed a spasm to have caused it. Köster (1906) found transitory reduction of the field of vision in patients suffering from polycythaemia and supposed it to have originated in a spasm of the cerebral artery. Ultimately Mylius (1928) was the first to observe a transitory spasm of all the branches of the central retinal artery in one eye of a patient suffering from polycythaemia. Later Lisch (1940) reported a similar case with temporary spasm of the central retinal artery. Thus, all in all,

* Received for publication August 6, 1949. 
two cases are known in which it was possible to observe the supposed artery spasms and to photograph them.

This communication contains observations of changes of the fundus in thirteen cases of polycythaemia. With new data it aims at confirming the observations and suppositions of Mylius (1928) and Lisch (1940), i.e., that the role of the arteries is not unimportant in the picture of the fundus in polycythaemia. Some of the patients were observed for several months and many examinations were necessary in order to identify different signs.

\section{Details of Two Cases}

Case 1.-Male patient, 24 years old, suffering from polycythaemia for one year. A few months previously his left arm and left leg became paralysed for several weeks; later the paralysis subsided. For the last two weeks he had temporarily

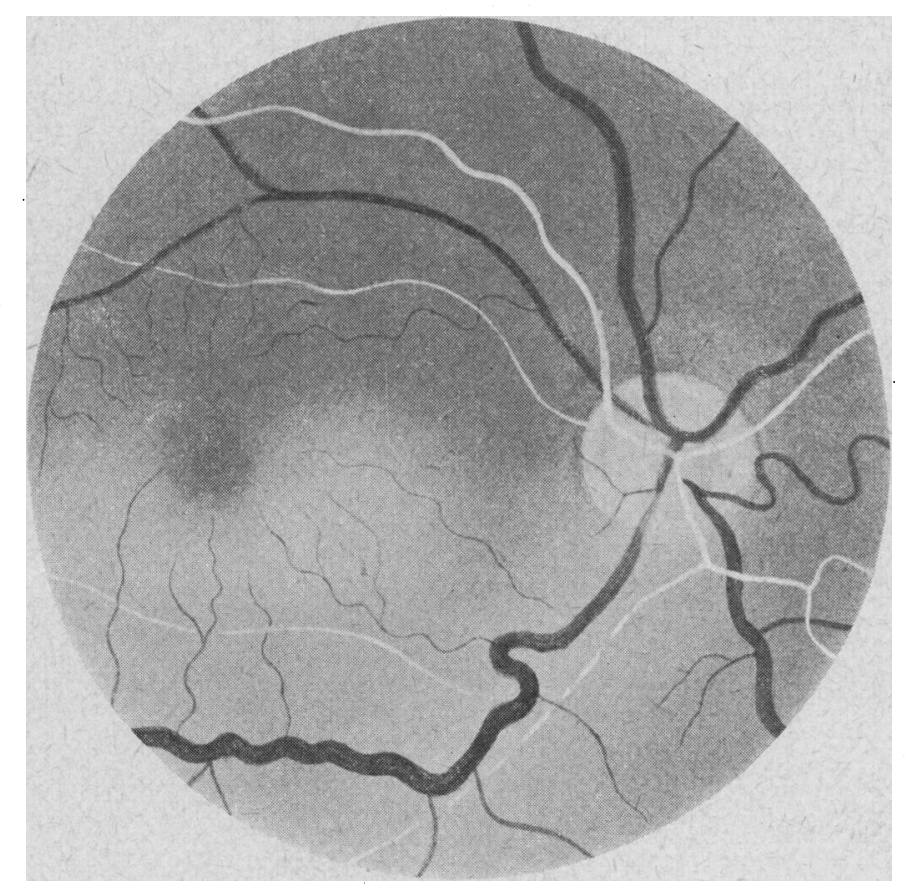

FIG. 1.-Case 1, male patient, 24 years old, right eye.

lost the sight of the right eye completely for a few minutes. During the last four days, however, amidst similar symptoms, vision in the right eye had suddenly deteriorated and not returned. 
The medical report was as follows: Red blood corpuscles count, 8.8 million; blood-pressure, 150/120; tumour of the spleen; liver swelling.

The ophthalmological report was as follows: Visual acuity in the right eye, finger count at $1 / 2 \mathrm{~m}$; left eye $5 / 5$; fundus in right eye; lower nasal border of the optic nerve blurred. The central retinal artery under the temporal branch near the disk was highly narrowed, the blood column inside was interrupted in several places. Alongside the vein the retina was oedematous and greyish-white, the oedema extending as far as the lower half of the macula, the fovea brighter red. The veins were dilatated to three times their normal size in places, especially the lower temporal vein. On the periphery in the direction of 2 o'clock a few thin, white, thread-like, empty arteries and small punctate haemorrhages. The left eye showed no visible changes except considerable dilatation of the veins.

During one of the examinations all the arteries of the right fundus suddenly turned into white, thread-like structures, while the small arteries disappeared, the blood column being completely expressed from them. This could be observed and photographed twice. Fig. 1 shows a drawing of a photograph of the fundus. On both occasions the lumen of the arteries gradually reopened in 10-15 minutes. During the phenomenon the patient had felt nothing at all, and the oedema remained unchanged. Visual acuity deteriorated during the spasm to seeing movements of the hand. About two weeks later, after different vasodilators and spasmolytics had been administered, the spasm of the lower temporal artery was relieved, the oedema disappeared, and visual acuity improved to $5 / 20$, the field of vision being greatly reduced.

Case 2.--Female patient, 40 years old, under treatment for five years.

The medical report was as follows: Red blood corpuscles count, 6.5-7.5 million; blood pressure, 170/120; large tumour of the spleen; liver swollen; myocardial lesion.

The ophthalmological report was as follows: Vision blurred from time to time, the right eye being sometimes absolutely sightless for 1-2 days. Once we succeeded in observing a spasm like that described in Case 1 ; it expanded to all the branches of the arteries and lasted for only a short time during which the arteries turned into white thread-like structures. The picture resembled that shown in Fig. 1 without the oedema. Visual acuity of the right eye deteriorated to finger count at $1 \mathrm{~m}$. distance, but after the spasm had ended, sight was completely restored within a few minutes.

\section{Discussion}

The complete absence of blood in the arteries as shown in Fig. 1 is a change which can so rarely be observed that in other diseases (eclampsia, migraine, etc.) it has hardly ever been possible to find it so soon. After the spasm had ended, it was so evident that the arteries filled again from the direction of the disk that there could be no doubt as to their having been emptied by the spasm. Besides the cases of Mylius and Lisch, my Case 1 is-as far as I know-the third to be described in literature, and my Case 2 is the fourth in which a similar complete spasm could be observed.

Unlike the other cases, in my Case 2 broad white stripes could be seen alongside the walls of the arteries and veins, probably because of changes in the walls and their direct surroundings, which were certainly related to the lasting spastic state. 
My third case is an example of the finding of Uhthoff, who believes that the partial dilatations of the veins are most characteristic. In Fig. 2 we can see such a partial ectasia in one of the nasal veins, which was all the more striking as it was a much darker red. Dilatations of the veins to so high a degree, and such distinct tortuousness of even the smallest veins, generally only occur after a long time and usually only when the heart is no

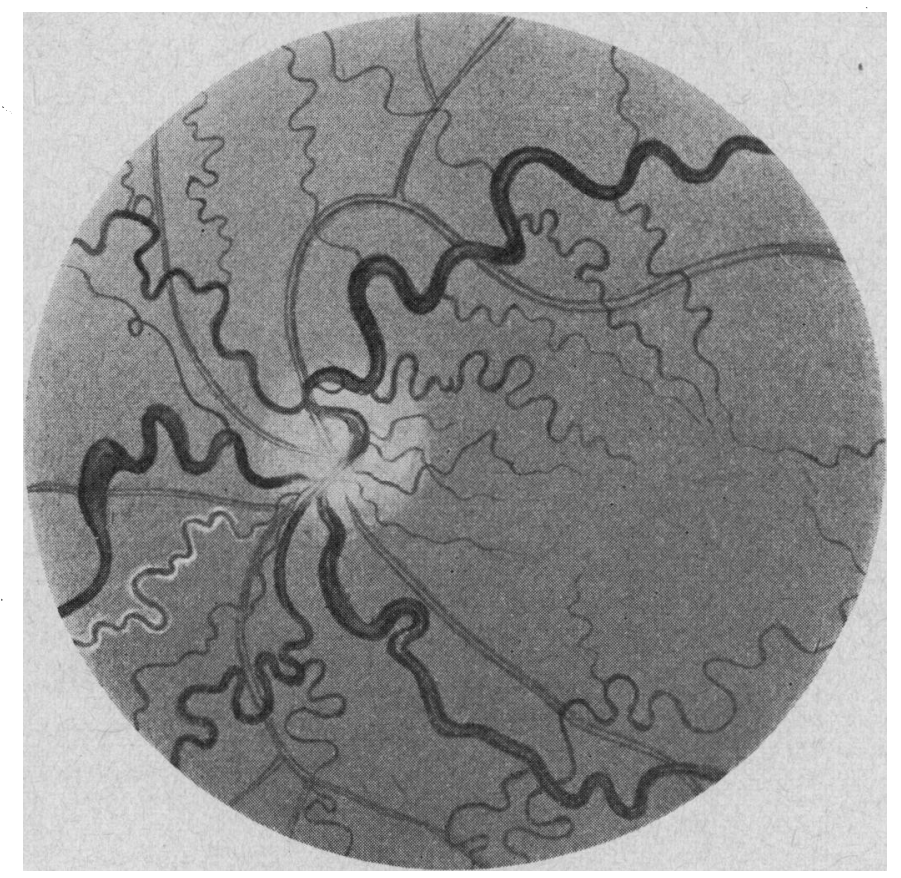

Fig. 2.-Case 3, example of partial dilatation of vein as described by Uhthoff.

longer strong. Papilloedema is also visible in Fig. 2, but this was much more developed in another case. Among my cases I also found an example of the formation of new blood vessels, and retinal haemorrhages.

In the other cases the pictures of the fundi were not different from the well known type of fundus polycythaemicus. In every case the darker red colour and the dilated veins could be observed, so that the fundus was characteristic of the disease in every case. In one case it was the examination of the fundus which suggested polycythaemia, and the medical report justified this suggestion. 


\section{Summary}

When determining fundus polycythaemicus we must scrutinize the arteries as well as the veins. Among thirteen patients we observed important changes of the arteries in two and we succeeded in observing a spasm which spread to all the branches of the central retinal artery. On account of this case and two others, previously reported in the literature, we must consider spasm of the central retinal artery to be the cause of transitory deterioration of vision in patients suffering from polycythaemia. Temporary paralysis of the extremities must also be attributed to prolonged spasm of the cerebral vessels.

\section{REFERENCES}

BEHR. Cited in Leber, T. (1915), Graefe-Saemisch's "Handbuch der Augenheilkunde"', vol. 7, abt. 1. and HEGNER. Ibid.

Elsnig, A., and NonnenBRuch, W. (1932). Klin. Mbl. Augenheilk., 88, 433.

Köster, G. (1906). Mïnch. med. Wschr., 53, 1056.

Liebreich. Cited in Leber, T. (1915), Graefe-Saemisch's " Handbuch der Augenheilkunde, Vol. 7, abt. 1.

Lisch, K. (1939). Klin. Mbl. Augenheilk., 104, 157.

Litauer, R., and JaNUSZEVESKi, Z. (1934). Klin. oczna, 12, 618.

Mylius, K. (1928). Beihefte $Z$. Augenheilk., 10.

ОнASHI, K., and OKADA, K. (1939). Chuo-Ganka-Iho, 31, 1.

RAYNAUD. Cited in Leber, T. (1915), Graefe-Saemisch's " Handbuch der Augenheilkunde"', Vol. 7, abt. 1.

Uнtноғғ, W. (1906). Klin. Mbl. Augenheilk., 44, 449. 